\title{
Reduced $\beta$-cell function in early preclinical type 1 diabetes
}

\author{
Maarit K Koskinen ${ }^{1,2}$, Olli Helminen ${ }^{3,4}$, Jaakko Matomäki' ${ }^{5}$, Susanna Aspholm ${ }^{6,7,8}$, \\ Juha Mykkänen ${ }^{1}$, Marjaana Mäkinen ${ }^{1,2}$, Ville SimelI ${ }^{2}$, Mari Vähä-Mäkilä', \\ Tuula Simell $^{9,10}$, Jorma Ilonen ${ }^{11,12}$, Mikael Knip ${ }^{6,13,14,15}$, Riitta Veijola ${ }^{3,4}$, \\ Jorma Toppari ${ }^{1,16, *}$ and Olli Simell ${ }^{1,10, *}$ \\ ${ }^{1}$ Department of Paediatrics, University of Turku and Turku University Hospital, Turku, Finland, \\ ${ }^{2}$ MediCity Laboratories, Department of Clinical Medicine, University of Turku, Lemminkäisenkatu 3, 20520 Turku, \\ Finland, ${ }^{3}$ PEDEGO Research Unit, Department of Paediatrics, Medical Research Centre Oulu, University of Oulu, \\ Oulu, Finland, ${ }^{4}$ Department of Children and Adolescents, Oulu University Hospital, Oulu, Finland, \\ ${ }^{5} \mathrm{Clinical}$ Research Centre, Turku University Hospital, Turku, Finland, ${ }^{6}$ Department of Paediatrics, Tampere University \\ Hospital, Tampere, Finland, ${ }^{7}$ Novo Nordisk Farma Oy, CMR Department, Espoo, Finland, ${ }^{8}$ Diabetes Outpatient Clinic, \\ Tampere, Finland, ${ }^{9}$ Department of Paediatrics, Turku University Hospital, Turku, Finland, ${ }^{10}$ Research Centre of \\ Applied and Preventive Cardiovascular Medicine, University of Turku, Turku, Finland, ${ }^{11}$ Immunogenetics Laboratory, \\ University of Turku, Turku, Finland, ${ }^{12}$ Department of Clinical Microbiology, University of Eastern Finland, Kuopio, \\ Finland, ${ }^{13}$ Children's Hospital, University of Helsinki and Helsinki University Hospital, Helsinki, Finland, \\ ${ }^{14}$ Research Programs Unit, Diabetes and Obesity, University of Helsinki, Helsinki, Finland, ${ }^{15}$ Folkhälsan Research \\ Centre, University of Helsinki, Helsinki, Finland and ${ }^{16}$ Department of Physiology, Institute of Biomedicine, \\ University of Turku, Turku, Finland \\ *(J Toppari and O Simell contributed equally to this work)
}

Correspondence should be addressed to M K Koskinen Email maarit.koskinen@utu.fi

\begin{abstract}
Objective: We aimed to characterize insulin responses to i.v. glucose during the preclinical period of type 1 diabetes starting from the emergence of islet autoimmunity.

Design and methods: A large population-based cohort of children with HLA-conferred susceptibility to type 1 diabetes was observed from birth. During regular follow-up visits islet autoantibodies were analysed. We compared markers of glucose metabolism in sequential intravenous glucose tolerance tests between 210 children who were positive for multiple $(\geq 2)$ islet autoantibodies and progressed to type 1 diabetes (progressors) and 192 children testing positive for classical islet-cell antibodies only and remained healthy (non-progressors).

Results: In the progressors, the first phase insulin response (FPIR) was decreased as early as 4-6 years before the diagnosis when compared to the non-progressors $(P=0.001)$. The difference in FPIR between the progressors and non-progressors was significant $(P<0.001)$ in all age groups, increasing with age (at 2 years: difference $50 \%(95 \% \mathrm{Cl} 28-75 \%)$ and at 10 years: difference $172 \%(95 \% \mathrm{Cl} 128-224 \%))$. The area under the 10-min insulin curve showed a similar difference between the groups $(P<0.001$; at 2 years: difference $36 \%$ (95\% Cl 17-58\%) and at 10 years: difference $186 \%(95 \% \mathrm{Cl} 143-237 \%)$ ).
\end{abstract} Insulin sensitivity did not differ between the groups. Conclusions: FPIR is decreased several years before the diagnosis of type 1 diabetes, implying an intrinsic defect in $\beta$-cell mass and/or function.

\section{Introduction}

Type 1 diabetes is an autoimmune disease leading to the loss of insulin secretion from the pancreatic $\beta$-cells, which ultimately results in high circulating plasma glucose levels and clinical symptoms (1). Islet autoantibodies are predictive of the disease, and in children they typically appear within the first years of life $(2,3,4)$.
(C) 2016 The authors Published by Bioscientifica Ltd.
European Journal of

Endocrinology

(2016) 174, 251-259 
Currently, type 1 diabetes is diagnosed at a younger age than previously $(5,6)$.

One of the most commonly used methods to assess the capacity of the $\beta$-cells to secrete insulin is the intravenous glucose tolerance test (IVGTT), where the first $10 \mathrm{~min}$ represent the initial burst, the acute insulin response to a rapid glucose stimulus (7). It occurs via the release of insulin from the membrane-docked secretory granules within the $\beta$-cells (8). First phase insulin response (FPIR), calculated as the sum of serum insulin concentrations at 1 and $3 \mathrm{~min}$ in the IVGTT, has been shown to decline before the diagnosis $(9,10,11)$ and a reduced FPIR clearly predicts clinical type 1 diabetes $(12,13,14,15)$. Overall, the loss of FPIR has been considered to be a rather late sign of the disease process and a marker of $\beta$-cell pathology. However, when FPIR was analysed shortly after seroconversion in a cross-sectional setting in the Type 1 Diabetes Prediction and Prevention (DIPP) Study, $55 \%$ (18 of 33 ) of children with biochemically defined autoantibodies had reduced FPIR values whereas 21\% (four of 19) of those with only islet autoantibodies had decreased FPIR (16). In the Diabetes Prevention Trial-type 1 where the longitudinal pattern of decline in FPIR was analysed, FPIR appeared to decline already between 4.4 and 1.5 years before diagnosis (9). Furthermore, the baseline FPIR was lower in those who progressed to type 1 diabetes than that in the non-progressors, also suggesting early dysfunction of $\beta$-cells (9).

The aim of the present study was to investigate the longitudinal pattern of initial insulin responses during sequential IVGTTs from the onset of islet autoimmunity.
We present the results of an analysis comparing FPIR values in children who had multiple islet autoantibodies and developed clinical diabetes during the follow-up and in children who remained healthy but were positive for classical islet-cell antibodies (ICA) alone, a group which actually has been shown to be at a low risk for developing type 1 diabetes (17).

\section{Subjects and methods}

\section{Study design}

The Finnish DIPP Study, launched in 1994, is an ongoing population-based prospective study in Turku, Oulu and Tampere University Hospitals, Finland. In the DIPP Study, cord blood is used for screening infants for HLA-conferred risk for type 1 diabetes (18). Families with a baby carrying HLA risk alleles are invited for follow-up starting when the infant is 3 months old until at least to the age of 15 years. The children are regularly tested for signs of $\beta$-cell autoimmunity. Follow-up visits are scheduled every 3-6 months until the age of 2 years and every 6-12 months thereafter. If a child develops islet autoantibodies, the follow-up interval becomes 3 months until the study endpoint is reached.

\section{Study participants}

Characteristics of the study children are presented in Table 1 . Originally, a series of children $(n=685)$ with at least one IVGTT performed after the initial appearance of

Table 1 Characteristics of the study children.

\begin{tabular}{l} 
Clinical characteristics \\
\hline Number of subjects \\
Sex, male (\%) \\
Age at seroconversion (any autoantibody, age in years) ${ }^{d}$, \\
median (min-max) \\
Age when persistently positive for two autoantibodies \\
(years) $^{d}$, median (min-max) \\
Age at diagnosis (years), median (min-max) \\
Follow-up time (years), median (min-max) \\
Number of IVGT tests
\end{tabular}

\begin{tabular}{c}
\hline Non-progressors $^{\mathrm{a}}$ \\
\hline 192 \\
$116(60.4 \%)$ \\
$4.59(0.65-12.60)$ \\
- \\
- \\
$12.02(2.45-15.54)$ \\
$318^{\mathrm{g}, \mathrm{h}}$ \\
\hline
\end{tabular}

\begin{tabular}{|c|c|}
\hline Progressors $^{b}$ & $P$ value \\
\hline $\begin{array}{c}210 \\
117(55.7 \%) \\
1.55(0.51-10.59)^{\mathrm{e}}\end{array}$ & $\begin{array}{r}0.34^{c} \\
<<0.001\end{array}$ \\
\hline $2.02(0.80-10.59)^{\mathrm{e}}$ & \\
\hline $\begin{array}{c}6.58(1.63-16.11) \\
5.49(0.45-16.09) \\
661^{h, i}\end{array}$ & $<0.001$ \\
\hline
\end{tabular}

${ }^{a}$ Non-progressors tested positive for islet-cell antibodies (ICA) only and did not develop clinical disease during the follow-up.

${ }^{b}$ Progressors are children with multiple $(\geq 2)$ islet autoantibodies who subsequently progressed to type 1 diabetes.

${ }^{c} \chi^{2}$ test.

${ }^{\mathrm{d}}$ Seroconversion to autoantibody positivity was defined based on positivity for a minimum of one autoantibody in at least two consecutive samples. Persistent positivity for multiple $(\geq 2)$ autoantibodies refers to positivity for a minimum of two autoantibodies in at least two consecutive samples.

$\mathrm{e}_{n}=193$, there were 17 siblings among the progressors whose follow-up started later than at birth. As their seroconversion date was not clearly defined, they were not included in these specific analyses.

${ }^{\mathrm{f}}$ Mann-Whitney $U$ test.

9Tests were performed in the Turku centre.

${ }^{\mathrm{h}}$ Analyses of glucose at $60 \mathrm{~min}$ were performed with the data from the Turku centre (299 samples from non-progressors and 325 samples from progressors).

i A total of 326 IVGTTs were performed in the Oulu and Tampere centres and 335 IVGTTs in the Turku centre. 
islet autoantibodies during the years 1995-2013 was compiled from the three clinical centres. We selected two groups for the current analyses: i) children who had multiple autoantibodies and progressed to type 1 diabetes by the end of June 2013 (progressors; $n=210$ ) and ii) children who remained healthy during the follow-up and carried a relatively low risk of type 1 diabetes - based on persistent or transient positivity for ICA only from the time of the initial seroconversion without other emerging autoantibodies during follow-up (non-progressors; $n=192)$. The 283 children with other autoantibody combinations and remaining non-diabetic were not included in the current analyses.

The autoantibody status was determined based on samples analysed by the beginning of August 2013. Children were diagnosed with type 1 diabetes based on the World Health Organization (WHO) criteria (19). In addition to index children that were observed from birth, 17 siblings were included in the group of progressors with a median follow-up time of 2.92 years (range 0.45-9.30 years) before diagnosis. Part of the study children $(n=155$, $38.6 \%$ of all) were involved in the DIPP nasal insulin trial which showed no protective effect by intranasal insulin (20). There were no differences in the baseline FPIR ( $P=0.29$ ) or in the changes from the baseline FPIR to the last FPIR $(P=0.81)$ between the placebo and nasal insulin groups in the DIPP intervention trial. Accordingly, their data were included in the current analyses. The seroconversion age was younger and the follow-up time shorter among the progressors compared to non-progressors (Table 1).
The present study was conducted according to the guidelines of the Declaration of Helsinki, and was approved by the Joint Commission on Ethics of Turku University and Turku University Central Hospital. Written informed consent was obtained from all subjects and/or their guardians.

\section{$\beta$-cell autoimmunity}

Four types of islet autoantibodies were analysed: ICA, insulin autoantibodies (IAA), antibodies to glutamic acid decarboxylase (GADA) and tyrosine phosphatase-related insulinoma-associated 2 molecule (IA-2A) $(17,21)$. The autoantibody analyses and cut-off limits have been described earlier (21).

\section{Intravenous glucose tolerance tests}

IVGTTs were performed in children with islet autoantibodies to evaluate $\beta$-cell function. The tests in this study were performed between May 1996 and May 2012 according to a standard protocol (22). Briefly, after overnight fasting and the use of local anaesthetic (EMLA, AstraZeneca), the fasting samples were drawn through an i.v. cannula at 5 and 0 min before the start of the glucose infusion. The glucose dose $(0.5 \mathrm{~g} / \mathrm{kg}$, maximum $35 \mathrm{~g})$ was infused through the cannula in $3 \mathrm{~min} \pm 15 \mathrm{~s}$, and samples were subsequently taken at 1, 3, 5 and 10 min after the end of the infusion. The recommended interval for IVGTTs in autoantibody positive DIPP children was every 6-12 months.

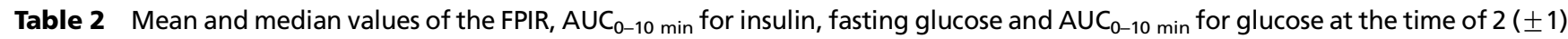
years prior to diagnosis in progressor children when single autoantibody (IAA, GADA or IA-2A) at seroconversion could be determined. ${ }^{\text {a,b }}$

\begin{tabular}{|c|c|c|c|c|}
\hline Glucose metabolism markers & GADA & IA-2A & IAA & $\boldsymbol{P}^{c}$ \\
\hline$n$ & 27 & 8 & 36 & \\
\hline \multicolumn{5}{|l|}{ FPIR } \\
\hline Mean (S.D.) & $48(51)$ & $48(27)$ & 34 (19) & 0.60 \\
\hline Median (min-max) & $36(11-274)$ & $46(9-92)$ & $31(11-86)$ & \\
\hline \multicolumn{5}{|l|}{$\mathrm{AUC}_{0-10 \mathrm{~min}}$ for insulin } \\
\hline Mean (s.D.) & $176(197)$ & $201(133)$ & $143(68)$ & 0.99 \\
\hline Median (min-max) & $123(51-1031)$ & $171(33-465)$ & $128(54-316)$ & \\
\hline \multicolumn{5}{|l|}{ Fasting glucose (mmol/l) } \\
\hline Mean (s.D.) & $4.8(0.4)$ & $4.9(0.6)$ & $4.7(0.6)$ & 0.22 \\
\hline Median (min-max) & $4.8(3.8-5.5)$ & $5.0(3.8-5.8)$ & $4.7(3.3-6.0)$ & \\
\hline $\mathrm{AUC}_{0-10 \mathrm{~min}}$ for glucose & & & & 0.40 \\
\hline Mean (s.D.) & $168(17)$ & $169(24)$ & $161(14)$ & \\
\hline Median (min-max) & $170(138-196)$ & $169(156-210)$ & 162 (136-194) & \\
\hline
\end{tabular}

aCA was not included in this spesific analysis.

${ }^{b}$ Children with multipositivity at seroconversion were not included in this analysis as the first autoantibody could not be determined.

${ }^{c}$ Overall $P$ value in one-way ANOVA. 


\section{Analyses of plasma glucose and serum insulin}

Plasma glucose concentrations were measured by an enzymatic method (23). For the quantitative serum insulin measurements an ELISA (Insulin ELISA Kit, Dako, Glostrup, Denmark) method (24) was used in the Oulu centre for samples obtained in Oulu and Tampere. In Turku, the method for serum insulin measurement has changed twice during the DIPP Study. From the beginning of the study until March 2001 a RIA (Phasadeph, Pharmacia) was used. Between March 2001 to November 2004 a time-resolved immunofluorimetric assay (TR-IFMA, Autodelfia, Wallac, Turku, Finland) was applied. The currently used method is an electrochemiluminescence immunoassay (ECLIA, Roche Diagnostics). The changes in the insulin concentrations have been small when comparing the different methods used in Turku: there was an increase by $1 \%$ after changing to TR-IFMA and a decrease by $3 \%$ since the change to ECLIA.

We have previously compared the insulin assays in the Oulu and Turku laboratories (16) and used a regression transformation equation to make the values from the Oulu laboratory comparable with the Turku RIA values. We also corrected the insulin concentrations obtained with the more recent Turku assays to make them comparable with the concentrations generated with the initial Turku RIA.

\section{Variables used to assess glucose metabolism}

$\beta$-cell function was evaluated by FPIR and the area under the $0-10$ min insulin curve ( $\mathrm{AUC}_{0-10 \mathrm{~min}}$ for insulin). As surrogate markers for insulin sensitivity, fasting insulin concentrations, the insulin resistance index determined by the homeostasis model assessment (HOMA-IR) (25) and the HOMA-IR to FPIR ratio (relative insulin resistance) were used. Fasting values for insulin and glucose were calculated as the mean of -5 and 0 min values from the IVGTT. When the fasting insulin values were below the detection limit, that limit was used as an actual value. Glucose values at $60 \mathrm{~min}$ from the Turku data set were analysed to investigate the late-phase glucose concentrations.

\section{Statistical analysis}

The response variables (glucose metabolism markers) were log-transformed for the analyses. Time periods of $0-2,2-4$ and 4-6 years before diagnosis (progressors) or the last IVGTT (non-progressors) were analysed separately. The progressors' last response variable before diagnosis (median 2.86 years before diagnosis; range from 5 days to
14 years) was compared with the previous one by a paired samples $t$-test. The median time between the last two measurements was 1.05 years (range: $0.23-4.71$ years). Owing to skewed distribution of the age at seroconversion and follow-up time, the comparisons between the study groups were performed with the Mann-Whitney $U$ test.

The scatterplots between age and response variables were noisy, so the data was explored using cubic splines (26) to smooth curves in order to reveal the mean or median response profile. To study the possible early differences between the two groups these analyses were also performed excluding data from last 2 years prior to diagnosis in the progressors. The patterns for females and males appeared similar and the combined profiles are shown.

The effect of age on response variables was assessed by a linear mixed model. Predictor variables were age, group and their interaction. Given estimates for age represent how response variables change when age is increased by 1 year. Study variables between the study groups were compared at the ages of 2, 4, 6, 8 and 10 years. In the age-dependent comparison, the difference between the study groups describes how many percent the response variable has changed in non-progressors compared to progressors.

Statistical analyses were performed with Statistical Analytical Software (SAS, version 9.3, SAS Institute, Cary, NC, USA) and Statistical Package for the Social Sciences (SPSS, version 21, IBM Corp., Armonk, NY, USA). Cubic splines were drawn using SAS GPLOT with SM30 interpolation parameter. $P$ values of $<0.05$ were considered statistically significant.

\section{Results}

\section{Metabolic changes before the diagnosis of type 1 diabetes}

FPIR and AUC $_{0-10 \text { min }}$ for insulin were decreased 0-2, 2-4 and 4-6 years before the diagnosis in the progressors as compared to the non-progressors $(P<0.005$, Fig. $1 \mathrm{~A}$ and $\mathrm{B})$. There was no difference in the fasting insulin concentrations between the groups (Fig. 1C). Fasting glucose concentrations increased during the last 6 months prior to diagnosis in the progressors (difference between the groups during $0-2$ years prior to diagnosis; $P<0.01$ ), while the groups did not differ from each other during the earlier time periods (Fig. 1D). HOMA-IR index did not differ between the groups before the diagnosis (Fig. 1E). HOMA-IR to FPIR ratio was increased in the progressors $0-2,2-4$ and $4-6$ years before the diagnosis $(P<0.01$; Fig. $1 F)$. 

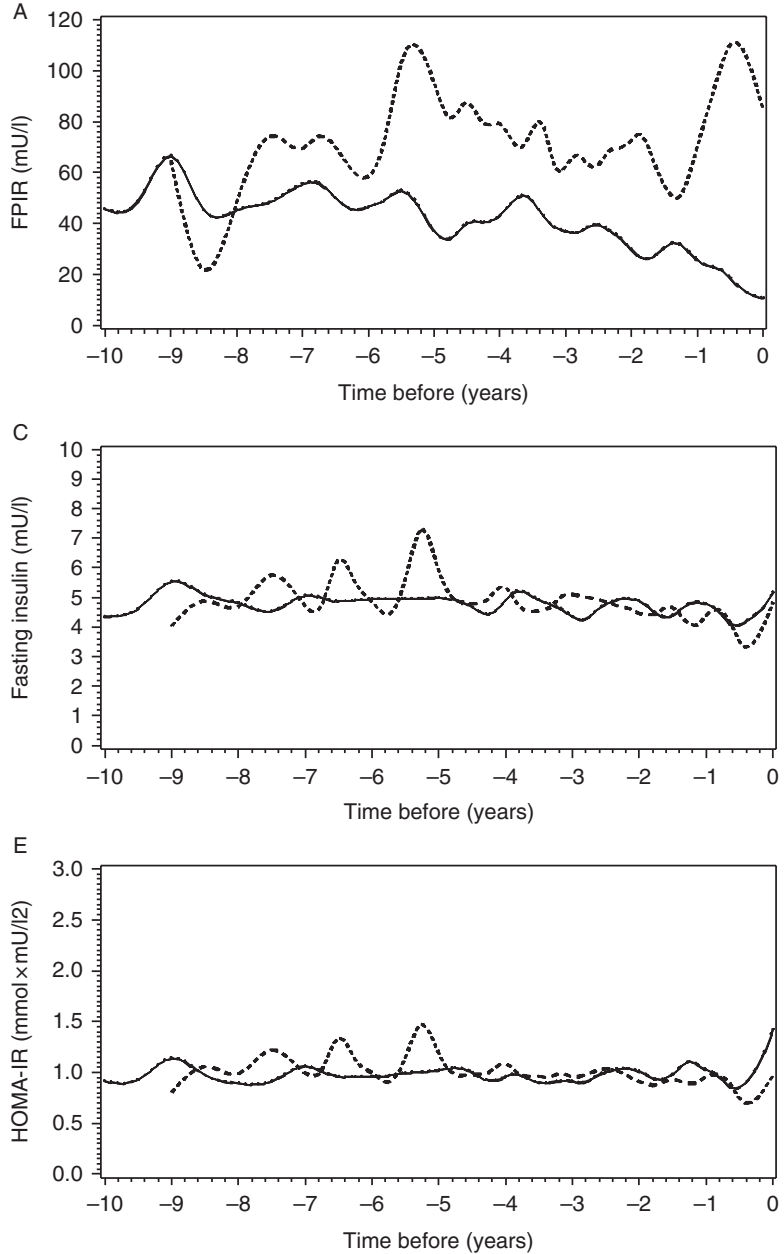

\section{Figure 1}

Median values of the study variables ((A) FPIR, (B) $A U C_{0-10 ~ m i n}$ for insulin, (C) fasting insulin, (D) fasting glucose, (E) HOMA-IR index and (F) HOMA-IR to FPIR ratio) before the diagnosis of type 1 diabetes in the progressors (black line) and in the non-progressors until the last IVGTT (dotted line). Point 0 indicates the time of the diagnosis or the last IVGTT. The $x$ axis indicates years before the diagnosis or the last IVGTT. (A and B) The $y$ axis indicates the unit

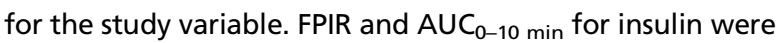
decreased $0-2$ and $2-4$ years $(P<0.001$ for both variables and time

In the last two samples before diagnosis, the change in FPIR, $\mathrm{AUC}_{0-10 \mathrm{~min}}$ for insulin, fasting glucose, HOMA-IR and the HOMA-IR to FPIR ratio reached significance $(P<0.005$; Supplementary Fig. S1A-B, D-F) whereas the increase in fasting insulin did not reach significance $(P=0.07$; Supplementary Fig. S1C).

There were no significant differences in the glucose metabolism markers when comparing progressor children
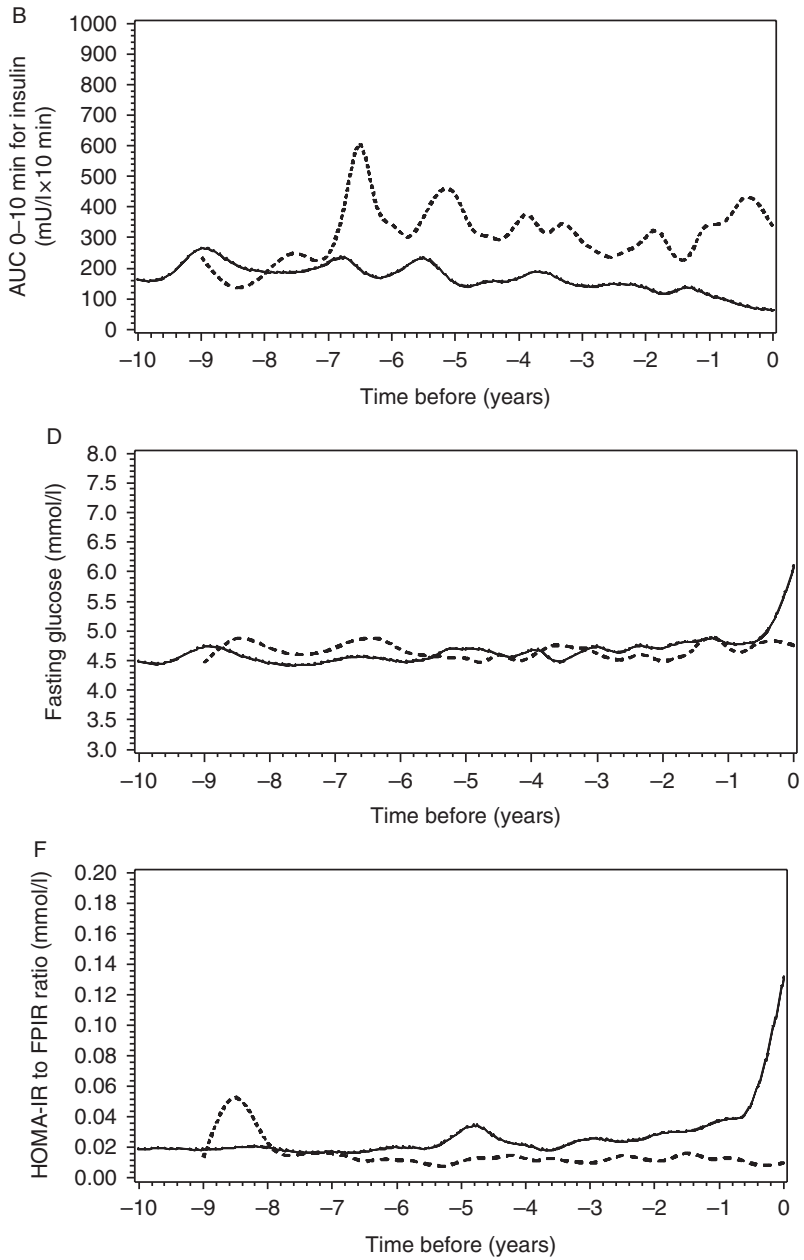

periods) and up to the time period of 4-6 years before the diagnosis as compared to the non-progressors $(P=0.001$ and $P=0.002$ respectively). (C) Fasting insulin did not differ between the groups before the diagnosis. (D) Fasting glucose differed between the groups $0-2$ years before the diagnosis $(P=0.008)$. (E) HOMA-IR index did not differ between the groups before the diagnosis. (F) HOMA-IR to FPIR ratio was increased in the progressors during the time periods $0-2,2-4$ and $4-6$ years prior to diagnosis ( $P<0.001, P<0.001$ and $P=0.005$ respectively).

who had different primary autoantibodies (IAA, GADA or IA-2A) at seroconversion (Table 2).

\section{Longitudinal age-dependent comparisons between the study groups}

The difference in FPIR between the progressors and nonprogressors was significant in all age groups $(P<0.001)$. 
FPIR was higher in the non-progressors than in the progressors, and the difference increased with age (at 2 years: difference $50 \%(95 \%$ CI $28-75 \%)$ and at 10 years: difference $172 \%$ (95\% CI 128-224\%); Fig. 2A). AUC $\mathrm{A}_{-}$ 10 min for insulin showed a similar difference between the groups $(P<0.001$; at 2 years: difference 36\% (95\% CI $17-$ $58 \%$ ) and at 10 years: difference $186 \%$ (95\% CI 143-237\%); Fig. 2B).

The effect of age was similar in both study groups for fasting insulin and fasting glucose and HOMA-IR (the interaction between age and group was for these variables $P=0.11, P=0.16$ and $P=0.08$ respectively). Fasting insulin increased 3.9\% (95\% CI 2.5-5.2\%) per year, fasting glucose $0.50 \%$ (95\% CI 0.17-0.83\%) per year and HOMA-IR index
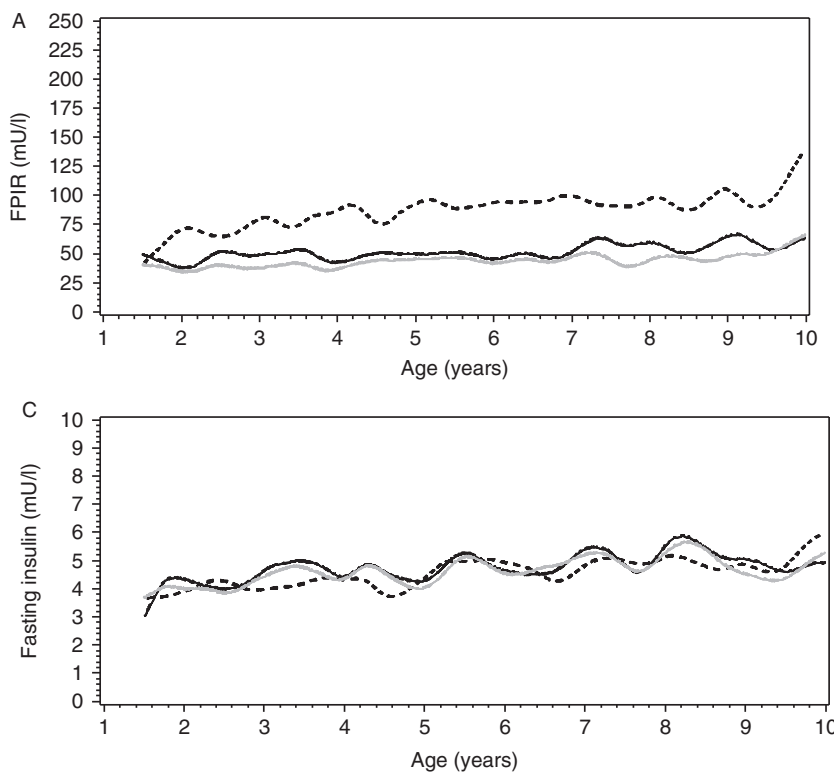

E

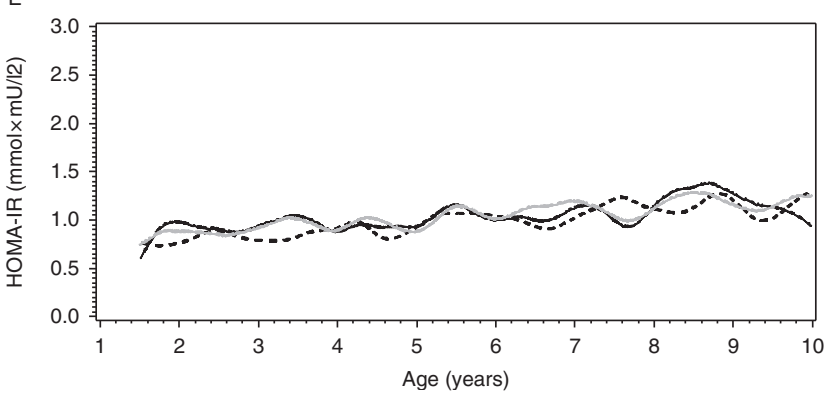

\section{Figure 2}

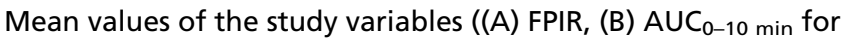
insulin, (C) fasting insulin, (D) fasting glucose, (E) HOMA-IR index and (F) HOMA-IR to FPIR ratio) in cubic splines between the non-progressors and progressors as a function of age (years). The solid line shows the values of the progressors. The black line represents the values when the last 2 years prior increased $4.4 \%$ (95\% CI 2.9-5.9\%) per year $(P<0.005$; Fig. 2C, D and E). HOMA-IR to FPIR ratio was lower in the non-progressors than in the progressors at all ages $(P<0.001$; at 2 years: difference $46 \%$ (95\% CI 36-54\%) and at 10 years: difference 60\% (95\% CI 52-67\%); Fig. 2D). There was no systematic effect of age on this variable because both the FPIR and HOMA-IR changed similarly with age.

Glucose at $60 \mathrm{~min} \triangleright$ By using the Turku data set only, the glucose at 60 min was increased in the progressors $0-2$ and 2-4 years before the diagnosis $(P<0.001$ and $P=0.03$ respectively; Fig. 3A). The change in glucose at $60 \mathrm{~min}$ was significant in the last two samples before diagnosis
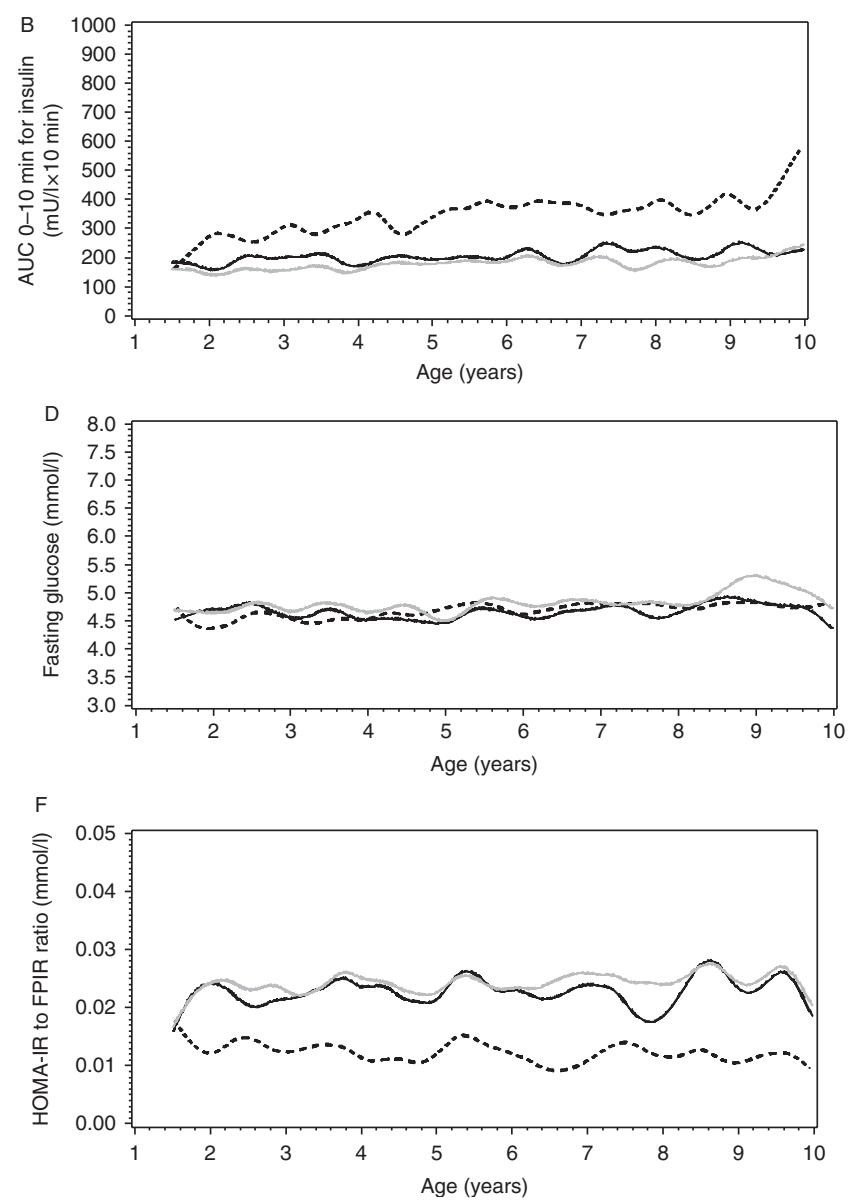

to diagnosis were excluded. The grey line represents the values when the last 2 years prior to diagnosis were included. The black dotted line represents the non-progressors. (C, D and E) Fasting insulin increased 3.9\%/year, fasting glucose $0.50 \% / y e a r$ and HOMA-IR index increased $4.4 \% /$ year $(P<0.001, P=0.0024$ and $P<0.001$ respectively). 

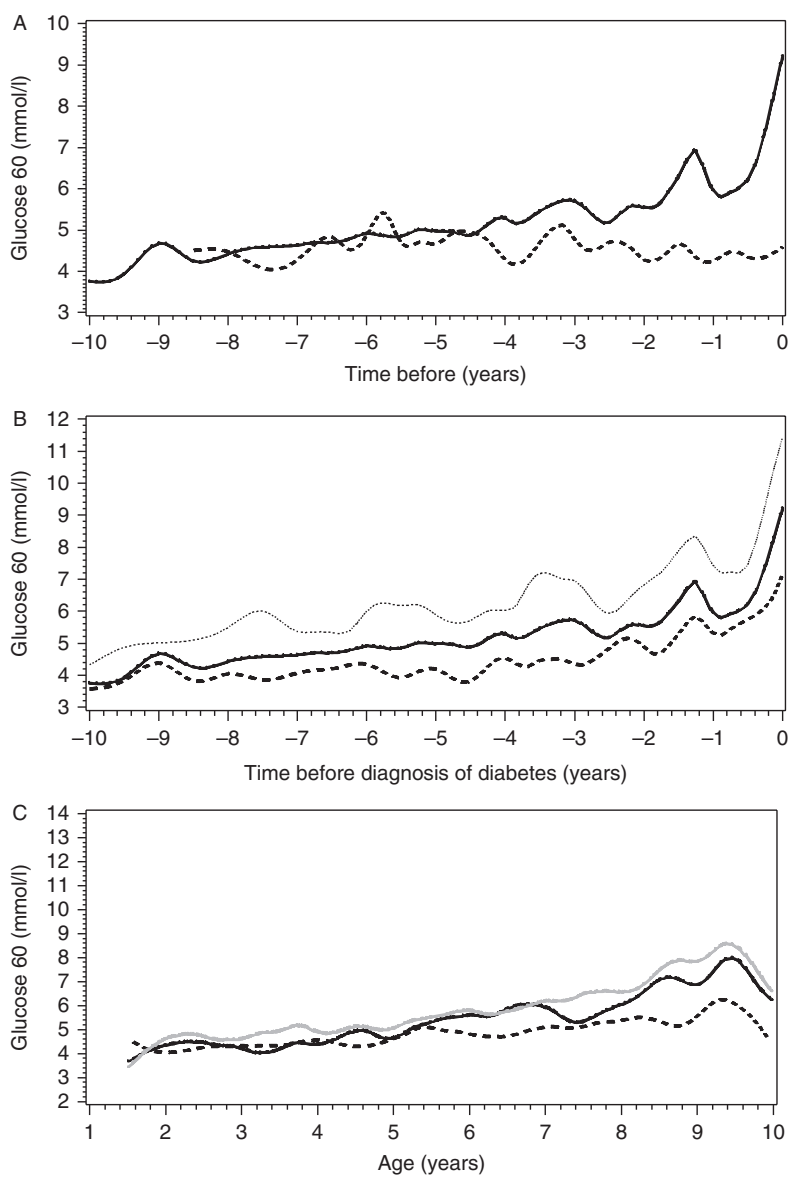

\section{Figure 3}

(A) Median 60-min values of glucose before the diagnosis of type 1 diabetes in the progressors (black line) and in the nonprogressors until the last IVGTT (dotted line). Point 0 indicates the time of the diagnosis or the last IVGTT. The $x$ axis indicates years before the diagnosis or the last IVGTT. The $y$ axis indicates plasma glucose concentration at 60 minutes. (B) The median, upper and lower quartile for 60 -min glucose values before the diagnosis of type 1 diabetes. Point 0 indicates the time of diagnosis. The $x$ axis indicates years before the diagnosis. The $y$ axis indicates plasma glucose concentration at 60 minutes. For other variables in this study, the quartiles before the diagnosis of type 1 diabetes are seen in the Supplementary File. (C) Mean values of glucose at $60 \mathrm{~min}$ in cubic splines among the non-progressors and progressors as a function of age (years). The solid line shows the values of the progressors. The black line represents the values when the last 2 years prior to diagnosis were excluded. The grey line represents the values when the last 2 years prior to diagnosis were included. The black dotted line represents the non-progressors. Glucose values at $60 \mathrm{~min}$ were obtained from the Turku data set (299 samples from non-progressors and 325 samples from progressors).
$(P<0.001$, Fig. 3B). Glucose at $60 \mathrm{~min}$ was lower in nonprogressors from the age of 6 years onwards and the difference increased with age $(P<0.001$; at 6 years: difference $11 \%$ (95\% CI 7-15\%) and at 10 years: difference 24\% (95\% CI 18-29\%); Fig. 3C).

\section{Discussion}

The results of this study show that $\beta$-cell function is reduced years before the diagnosis in children who progress to type 1 diabetes. The difference in FPIR between the progressors and non-progressors was evident 4-6 years before the diagnosis. In age-dependent longitudinal comparison, FPIR was constantly lower in the progressors than in the non-progressors, even when the FPIR values from the last 2 years prior to diagnosis were excluded from the analysis. The difference between the study groups increased with age: the mean FPIR was 2.7 times greater in the non-progressors than in the progressors at the age of 10 years. These findings imply that children at risk fail to increase their $\beta$-cell function adequately to maintain glucose homeostasis with age and increasing body size. Interestingly, in an earlier study ICA-negative siblings of patients with type 1 diabetes were described to have significantly lower FPIR from 8 years onwards when compared to control children (27).

The control group in this study (non-progressors) comprised children who tested positive for the classical ICA only. We have shown earlier that single temporary or persistent ICA positivity is associated with a 5-year cumulative risk of type 1 diabetes of only 1.4 and $4.7 \%$, respectively (17), which is rather similar to risk of Finnish children with no islet autoantibodies. The median seroconversion age of the non-progressors was 4.6 years, whereas the progressors seroconverted earlier, at the median age of 1.6 years, and developed multiple autoantibodies later. It is known that the presence of two or more autoantibodies substantially increases the risk of progression to clinical type 1 diabetes with a 5-year cumulative risk being around 40\%; in a 15 -year followup the risk is over $80 \%$ (28).

The baseline FPIR of the progressors and nonprogressors appears similar (Fig. 2A). However, no data from the first year of life was available for comparison. As the progressors seroconverted early, the low level of FPIR suggests a rapid autoimmune-mediated decline in $\beta$-cell function shortly after the appearance of autoantibodies. However, it is also possible that FPIR in the progressors was already low prior to this. During early childhood, $\beta$-cell mass grows rapidly by replication $(29,30)$. A high risk of 
type 1 diabetes could be associated with an already decreased $\beta$-cell mass at birth (31). As FPIR represents the response to glucose, it is also possible that $\beta$-cells have impaired glucose sensitivity in children at risk to develop type 1 diabetes $(32,33)$.

In both study groups, fasting insulin, fasting glucose and HOMA-IR index increased by age. Insulin resistance measured by HOMA-IR index does not appear to play a major role in the development of type 1 diabetes, which is in line with our earlier study in which the focus was on the predictive role of FPIR after the appearance of multiple islet autoantibodies (13). The difference between the groups in relative insulin resistance as assessed by HOMA-IR to FPIR ratio in this study was caused by the low FPIR in the progressors.

We also performed a separate analysis in the Turku cohort, where the glucose at $60 \mathrm{~min}$ was increased in the progressors 2-4 years before the diagnosis. In the retrospective comparison in our earlier study (34) the OGTTderived 2-h plasma glucose and random plasma glucose values were significantly different from those 1.5 years before diagnosis; thus, it seems these increased late phase glucose values in IVGTT precede abnormalities of OGTT before the diagnosis.

The strengths of this study include the long follow-up and the repeated monitoring of autoantibodies and IVGTTs in a large cohort of children observed from birth. The variation in the number and timing in the IVGTTs is a limitation of the current work but that was unavoidable in the young children.

To conclude, our study demonstrates that the insulin secretory capacity of the $\beta$-cells is compromised early during the disease process leading to type 1 diabetes. The low insulin response to glucose seems to be an essential feature of the disease process and suggests that children progressing to type 1 diabetes have an intrinsic impairment in their $\beta$-cell mass or function that further deteriorates under environmental pressure.

\section{Declaration of interest}

The authors declare that there is no conflict of interest that could be perceived as prejudicing the impartiality of the research reported.

\section{Funding}

This work was supported by The Juvenile Diabetes Research Foundation, USA, grants 4-1999-731 and 4-2001-435, by the Special Public Grants for Medical Research at Turku, Oulu and Tampere University Hospitals, the Academy of Finland (Centre of Excellence in Molecular Systems Immunology and Physiology Research 2012-17, decision no. 250114), the Foundation for Paediatric Research in Finland, the Diabetes Research
Foundation Finland, the grants from Alma and K.A. Snellman Foundation, Finland, the Signe and Ane Gyllenberg Foundation, the European Union Biomed, UTU GS Doctoral Programme and Sigrid Juselius Foundation.

\section{Author contribution statement}

M K Koskinen, O Simell, J Toppari and R Veijola contributed to the study design. M K Koskinen, O Helminen, S Aspholm, M Mäkinen, T Simell, J Ilonen, M Knip, R Veijola and O Simell contributed to the data acquisition. J Matomäki and M K Koskinen analysed the data. M K Koskinen, O Helminen, J Matomäki, J Mykkänen, M Vähä-Mäkilä, R Veijola, J Toppari and $\mathrm{O}$ Simell contributed to the interpretation of data. M K Koskinen, O Helminen, S Aspholm, J Mykkänen, M Mäkinen, V Simell, T Simell, J llonen, M Knip, R Veijola, J Toppari and O Simell contributed to the drafting of the work. M K Koskinen, O Helminen, J Matomäki, J Mykkänen, M Mäkinen, M Vähä-Mäkilä, V Simell, T Simell, M Knip, R Veijola, J Toppari and $O$ Simell critically revised the manuscript for important intellectual content. M K Koskinen and J Matomäki are the guarantors of this work and, as such, had full access to all of the data in the study and take responsibility for the integrity of the data and the accuracy of the data analysis.

\section{Acknowledgements}

Esko Pakarinen and Jari Hakalax are thanked for expert data managing. We also acknowledge the staff members in all three clinical DIPP Study centres. DIPP Study nurses, laboratory and technical staff are thanked for their skilfulness and dedication. In particular, we thank the children and parents participating in the DIPP Study.

\section{References}

1 Atkinson MA, Eisenbarth GS \& Michels AW. Type 1 diabetes. Lancet 2014383 69-82. (doi:10.1016/S0140-6736(13)60591-7)

2 Kimpimäki T, Kupila A, Hämäläinen AM, Kukko M, Kulmala P, Savola K, Simell T, Keskinen P, Ilonen J, Simell O et al. The first signs of $\beta$-cell autoimmunity appear in infancy in genetically susceptible children from the general population: the Finnish Type 1 Diabetes Prediction and Prevention Study. Journal of Clinical Endocrinology and Metabolism 200110 4782-4788. (doi:10.1210/jcem.86.10.7907)

3 Parikka V, Näntö-Salonen K, Saarinen M, Simell T, Ilonen J, Hyöty H, Veijola R, Knip M \& Simell O. Early seroconversion and rapidly increasing autoantibody concentrations predict prepubertal manifestation of type 1 diabetes in children at genetic risk. Diabetologia 2012 7 1926-1936. (doi:10.1007/s00125-012-2523-3)

4 Ziegler AG, Bonifacio E \& BABYDIAB-BABYDIET Study Group. Age-related islet autoantibody incidence in offspring of patients with type 1 diabetes. Diabetologia 20127 1937-1943. (doi:10.1007/ s00125-012-2472-x)

5 Patterson CC, Dahlquist GG, Gyurus E, Green A, Soltesz G \& EURODIAB Study Group. Incidence trends for childhood type 1 diabetes in Europe during 1989-2003 and predicted new cases 2005-20: a multicentre prospective registration study. Lancet 2009373 2027-2033. (doi:10.1016/S0140-6736(09)60568-7)

6 Harjutsalo V, Sjoberg L \& Tuomilehto J. Time trends in the incidence of type 1 diabetes in Finnish children: a cohort study. Lancet 2008371 1777-1782. (doi:10.1016/S0140-6736(08)60765-5)

7 Caumo A \& Luzi L. First-phase insulin secretion: does it exist in real life? Considerations on shape and function American Journal of Physiology 20043 E371-E385. (doi:10.1152/ajpendo.00139.2003)

8 Daniel S, Noda M, Straub SG \& Sharp GW. Identification of the docked granule pool responsible for the first phase of glucose-stimulated 
insulin secretion. Diabetes 19999 1686-1690. (doi:10.2337/diabetes. 48.9.1686)

9 Sosenko JM, Skyler JS, Beam CA, Krischer JP, Greenbaum CJ, Mahon J, Rafkin LE, Matheson D, Herold KC, Palmer JP et al. Acceleration of the loss of the first-phase insulin response during the progression to type 1 diabetes in diabetes prevention trial-type 1 participants. Diabetes 2013 12 4179-4183. (doi:10.2337/db13-0656)

10 Srikanta S, Ganda OP, Gleason RE, Jackson RA, Soeldner JS \& Eisenbarth GS. Pre-type I diabetes. Linear loss of $\beta$ cell response to intravenous glucose. Diabetes 19848 717-720. (doi:10.2337/diab.33. 8.717)

11 Colman PG, McNair P, Margetts H, Schmidli RS, Werther GA, Alford FP, Ward GM, Tait BD, Honeyman MC \& Harrison LC. The Melbourne Pre-Diabetes Study: prediction of type 1 diabetes mellitus using antibody and metabolic testing. Medical Journal of Australia 19982 81-84.

12 Vardi P, Crisa L \& Jackson RA. Predictive value of intravenous glucose tolerance test insulin secretion less than or greater than the first percentile in islet cell antibody positive relatives of type 1 (insulin-dependent) diabetic patients. Diabetologia 19912 93-102. (doi:10.1007/BF00500379)

13 Siljander HT, Hermann R, Hekkala A, Lähde J, Tanner L, Keskinen P, Ilonen J, Simell O, Veijola R \& Knip M. Insulin secretion and sensitivity in the prediction of type 1 diabetes in children with advanced $\beta$-cell autoimmunity. European Journal of Endocrinology 20134 479-485. (doi:10.1530/EJE-13-0206)

14 Bingley PJ. Interactions of age, islet cell antibodies, insulin autoantibodies, and first-phase insulin response in predicting risk of progression to IDDM in ICA+ relatives: the ICARUS data set. Islet Cell Antibody Register Users Study. Diabetes 199612 1720-1728. (doi:10.2337/diab.45.12.1720)

15 Vialettes B, Mattei-Zevaco C, Badier C, Ramahandridona G, Lassmann-Vague $\mathrm{V} \&$ Vague P. Low acute insulin response to intravenous glucose. A sensitive but non-specific marker of early stages of type 1 (insulin-dependent) diabetes. Diabetologia 19888 592-596. (doi:10.1007/BF00264765)

16 Keskinen P, Korhonen S, Kupila A, Veijola R, Erkkilä S, Savolainen H, Arvilommi P, Simell T, Ilonen J, Knip M et al. First-phase insulin response in young healthy children at genetic and immunological risk for type I diabetes. Diabetologia 200212 1639-1648. (doi:10.1007/ s00125-002-0981-8)

17 Siljander HT, Simell S, Hekkala A, Lähde J, Simell T, Vähäsalo P, Veijola R, Ilonen J, Simell O \& Knip M. Predictive characteristics of diabetes-associated autoantibodies among children with HLA-conferred disease susceptibility in the general population. Diabetes 200912 2835-2842. (doi:10.2337/db08-1305)

18 Ilonen J, Hammais A, Laine AP, Lempainen J, Vaarala O, Veijola R, Simell O \& Knip M. Patterns of $\beta$-cell autoantibody appearance and genetic associations during the first years of life. Diabetes $2013 \mathbf{1 0}$ 3636-3640. (doi:10.2337/db13-0300)

19 Alberti KG \& Zimmet PZ. Definition, diagnosis and classification of diabetes mellitus and its complications. Part 1: diagnosis and classification of diabetes mellitus provisional report of a WHO consultation. Diabetic Medicine 19987 539-553. (doi:10.1002/ (SICI) 1096-9136(199807)15:7 < 539::AID-DIA668 > 3.0.CO;2-S)

20 Näntö-Salonen K, Kupila A, Simell S, Siljander H, Salonsaari T, Hekkala A, Korhonen S, Erkkola R, Sipilä JI, Haavisto L et al. Nasal insulin to prevent type 1 diabetes in children with HLA genotypes and autoantibodies conferring increased risk of disease: a double-blind, randomised controlled trial. Lancet 2008372 1746-1755. (doi:10.1016/ S0140-6736(08)61309-4)

21 Kukko M, Kimpimäki T, Korhonen S, Kupila A, Simell S, Veijola R, Simell T, Ilonen J, Simell O \& Knip M. Dynamics of diabetes-associated autoantibodies in young children with human leukocyte antigenconferred risk of type 1 diabetes recruited from the general population. Journal of Clinical Endocrinology and Metabolism 20055 2712-2717. (doi:10.1210/jc.2004-1371)

22 Bingley PJ, Colman P, Eisenbarth GS, Jackson RA, McCulloch DK, Riley WJ \& Gale EA. Standardization of IVGTT to predict IDDM. Diabetes Care 199210 1313-1316. (doi:10.2337/diacare.15.10.1313)

23 Beach EF \& Turner JJ. An enzymatic method for glucose determination in body fluids. Clinical Chemistry $19586462-475$.

24 Andersen L, Dinesen B, Jorgensen PN, Poulsen F \& Roder ME. Enzyme immunoassay for intact human insulin in serum or plasma. Clinical Chemistry 19934 578-582.

25 Matthews DR, Hosker JP, Rudenski AS, Naylor BA, Treacher DF \& Turner RC. Homeostasis model assessment: insulin resistance and $\beta$-cell function from fasting plasma glucose and insulin concentrations in man. Diabetologia 19857 412-419. (doi:10.1007/BF00280883)

26 Reinsch CH. Smoothing by spline functions. Numerische Mathematik 196710 177-183. (doi:10.1007/BF02162161)

27 Carel JC, Boitard C \& Bougneres PF. Decreased insulin response to glucose in islet cell antibody-negative siblings of type 1 diabetic children. Journal of Clinical Investigation 19931 509-513. (doi:10.1172/ JCI116595)

28 Ziegler AG, Rewers M, Simell O, Simell T, Lempainen J, Steck A, Winkler C, Ilonen J, Veijola R, Knip M et al. Seroconversion to multiple islet autoantibodies and risk of progression to diabetes in children. Journal of the American Medical Association 201323 2473-2479. (doi:10.1001/jama.2013.6285)

29 Meier JJ, Butler AE, Saisho Y, Monchamp T, Galasso R, Bhushan A, Rizza RA \& Butler PC. Beta-cell replication is the primary mechanism subserving the postnatal expansion of $\beta$-cell mass in humans. Diabetes 20086 1584-1594. (doi:10.2337/db07-1369)

30 Meier JJ, Köhler CU, Alkhatib B, Sergi C, Junker T, Klein HH, Schmidt WE \& Fritsch H. Beta-cell development and turnover during prenatal life in humans. European Journal of Endocrinology 20103 559-568. (doi:10.1530/EJE-09-1053)

31 Atkinson MA, von Herrath M, Powers AC \& Clare-Salzler M. Current concepts on the pathogenesis of type 1 diabetes - considerations for attempts to prevent and reverse the disease. Diabetes Care 20156 979-988. (doi:10.2337/dc15-0144)

32 Mari A, Tura A, Natali A, Laville M, Laakso M, Gabriel R, Beck-Nielsen H, Ferrannini E \& RISC Investigators . Impaired $\beta$ cell glucose sensitivity rather than inadequate compensation for insulin resistance is the dominant defect in glucose intolerance. Diabetologia 20104 749-756. (doi:10.1007/s00125-009-1647-6)

33 Ferrannini E, Natali A, Muscelli E, Nilsson PM, Golay A, Laakso M, Beck-Nielsen H, Mari A \& RISC Investigators . Natural history and physiological determinants of changes in glucose tolerance in a non-diabetic population: the RISC Study. Diabetologia 20116 1507-1516. (doi:10.1007/s00125-011-2112-x)

34 Helminen O, Aspholm S, Pokka T, Ilonen J, Simell O, Veijola R \& Knip M. OGTT and random plasma glucose in the prediction of type 1 diabetes and time to diagnosis. Diabetologia 20158 1787-1796. (doi:10.1007/s00125-015-3621-9)

Received 6 July 2015

Revised version received 9 November 2015

Accepted 30 November 2015 